\title{
FGF7/FGFR2 signal promotes invasion and migration in human gastric cancer through upregulation of thrombospondin-1
}

\author{
TINGTING HUANG, LEI WANG, DIAN LIU, PIAO LI, HUIHUA XIONG, \\ LIANG ZHUANG, LI SUN, XIANGLIN YUAN and HONG QIU \\ Department of Oncology, Tongji Hospital, Tongji Medical College, Huazhong University \\ of Science and Technology, Wuhan, Hubei 430030, P.R. China
}

Received December 4, 2016; Accepted March 3, 2017

DOI: $10.3892 /$ ijo.2017.3927

\begin{abstract}
Fibroblast growth factor 7 (FGF7) is a mesenchyme-specific heparin-binding growth factor that binds FGF receptor 2 (FGFR2) to regulate numerous cellular and physiological processes. FGF7/FGFR2 signal is associated with gastric cancer progression. In the present study, we investigated the molecular mechanism by which FGF7/FGFR2 promotes invasion and migration in human gastric cancer. We first demonstrated that increased FGFR2 expression in human gastric cancer tissues was significantly associated with tumor depth and clinical stage in human gastric cancer tissues. Thrombospondin 1 (THBS1) is an extracellular glycoprotein that plays multiple roles in cellmatrix and cell-cell interactions. Increased expression of THBS1 significantly correlated with tumor differentiation. FGFR2 and THBS1 expression were both increased in cancer tissues as compared with adjacent normal tissues and their expression was positively correlated. In vitro, FGF7 stimulation of cell invasion and migration was partially suppressed by the FGFR 2 knockdown. In addition, FGF7/FGFR 2 upregulated THBS1, and cell invasion and migration were decreased by knockdown of THBS1. Furthermore, the $\mathrm{PI} 3 \mathrm{~K} / \mathrm{Akt} / \mathrm{mTOR}$ signaling pathway was predominantly responsible for FGF7/FGFR2-induced THBS1 upregulation. Taken together, our data suggest that FGF7/FGFR2/THBS1 is associated with the regulation of invasion and migration in human gastric cancer.
\end{abstract}

Correspondence to: Professor Hong Qiu, Department of Oncology, Tongji Hospital, Tongji Medical College, Huazhong University of Science and Technology, 1095 Jiefang Avenue, Wuhan, Hubei 430030, P.R. China

E-mail: tjqiuhong@163.com

Abbreviations: FGF, fibroblast growth factor; FGFR, fibroblast growth factor receptor

Key words: FGF7/FGFR2 signal, gastric cancer, invasion, migration, thrombospondin 1

\section{Introduction}

Gastric cancer is one of the most common cancers worldwide, with more than 900,000 new cases and 700,000 deaths each year (1). High-incidence areas include Eastern Asia, Central and Eastern Europe and South America (1). Current treatments to improve survival involve surgical resection, supplemented with neoadjuvant or adjuvant chemotherapy, with or without radiotherapy (2-4). Although the incidence of gastric cancer is decreasing, the prognosis is still among the poorest of all solid-organ tumors. The 5-year survival for stage IV disease rarely exceeds $5 \%$ and the median overall survival is less than 1 year $(5,6)$.

Fibroblast growth factors (FGFs) comprise a large family of heparin-binding growth factors that regulate numerous cellular and physiological processes including proliferation, angiogenesis, invasion and migration (7). FGFs carry out their diverse functions by binding and activating members of the FGF receptor (FGFR) family of tyrosine kinase receptors (8). FGF7, also known as keratinocyte growth factor is expressed specifically in mesenchyme (7). FGF7 exerts its effect in a paracrine manner and specifically activates the receptor tyrosine kinase FGFR2IIIb $(8,9)$. FGF7 binding forces FGFR2 dimerization, and in turn rapidly triggers several signal transduction pathways, including RAS-mitogen-activated protein kinase (MAPK) and phosphoinositide 3-kinase (PI3K) Akt signaling pathways, which play fundamental roles in tumor progression (10). The coexpression of FGF7 and FGFR2 in gastric and pancreatic cancers, as well as in lung adenocarcinomas, is associated with poor prognosis (11-13). Paradoxically, decreased expression of FGFR2 has been reported in several cancers (14-16). These contrasting and context-dependent roles of FGFR2 underscore the complexity of FGF7/FGFR2 signaling.

Thrombospondins are a family of homologous proteins that regulate cellular phenotype and extracellular structure during tissue genesis and remodeling (17). Thrombospondin 1 (THBS1) was the first member to be identified, and it is widely known as an endogenous inhibitor of angiogenesis (18). THBS1 is synthesized by many cell types and can be secreted to the extracellular matrix. Numerous cell assays attribute a role for THBS1 in cell invasion and migration (19-21). However, conflicting results were obtained in different cell types (22). In 
recent years, an increasing number of studies have suggested THBS1 as a poor prognosis and recurrence marker in various cancer types including glioma, melanoma, as well as ovarian and pancreatic carcinomas $(19,23-25)$. Of note, THBS1 is a multi-modular and multi-functional protein that exerts intricate and sometimes opposite effects on tumor progression.

Based on the previous reports, we hypothesized that FGF7/ FGFR2 signal promotes invasion and migration in human gastric cancer through regulation of THBS1. In the present study, we investigated the mechanisms of THBS1 regulation by FGF7/FGFR2, and we assessed the functional roles of FGF7/FGFR2/THBS1 in gastric cancer invasion and migration in vitro and in vivo.

\section{Materials and methods}

Tissue specimens. Fifty-three gastric cancer primary tissue samples and adjacent matched non-tumor tissue samples were collected between January 2014 and August 2014 after obtaining informed consent from the patients under institutional review board-approved protocols. None of the patients had received treatment prior to enrolment in the present study. All diagnoses were histopathologically confirmed. This study was approved by the institutional research ethics committee of Tongji Hospital of Tongji Medical College, Huazhong University of Science and Technology (Wuhan, China).

Immunohistochemistry (IHC). Formalin-fixed and paraffinembedded tissue sections ( $5 \mu \mathrm{m}$ thick) were deparaffinized, rehydrated, blocked of endogenous peroxidase and subjected to antigen retrieval. The sections were incubated with $5 \%$ bovine serum albumin (BSA) at room temperature for $30 \mathrm{~min}$ immediately followed by primary antibodies (FGFR2, 11835, 1:50; Cell Signaling Technology, Inc., Danvers, MA, USA; THBS1, TA325040, 1:100; Origene, Rockville, MD, USA) at $4^{\circ} \mathrm{C}$ overnight. After washing in Tris-buffered saline (TBS), the slides were reacted with peroxidase polymer-conjugated secondary antibody and DAB following counterstaining with hematoxylin. Primary antibodies were replaced by TBS as negative control. Each stained section was evaluated by two senior pathologists blinded to the clinical information, and conflicting cases were adjudicated by a third pathologist. Five fields were randomly selected and observed under a light microscope. The staining results were scored based on the percentage of positive cells $(0,<10 \%$ positive cells; $1,10-30 \%$ positive cells; $2,30-50 \%$ positive cells; and $3,>50 \%$ positive cells), as well as on staining intensity ( 0 for negative staining, 1 for weak staining, 2 for moderate staining and 3 for strong staining). IHC total score was calculated as the product of both scores, which ranged from 0 to 9 . The cut-off was arbitrarily defined as a score $\geq 4$ represents high expression and a score $<4$ indicates low expression.

Cell lines and reagents. Human gastric cancer cell lines SGC7901, MKN28 and NCI-N87, human colorectal cancer cell lines SW480, Caco2 and HCT116, human lung adenocarcinoma cell line A549, human nasopharyngeal carcinoma cell line CNE2, and human breast cancer cell lines SKBR3 and MDA-MB-231 were acquired from Oncology Laboratory of Tongji Hospital (Wuhan, China). Cells were maintained in
RPMI-1640 (Hyclone Laboratories, Inc., Logan, UT, USA) supplemented with $10 \%$ fetal bovine serum (FBS; Gibco, Waltham, MA, USA) at $37^{\circ} \mathrm{C}$ under a humidified $5 \% \mathrm{CO}_{2}$ atmosphere. FGF7 was purchased from PeproTech (Rocky Hill, NJ, USA). LY294002, U0126, SP600125, SB203580 and RAD001 were obtained from Promoter Biotechnology (Wuhan, China).

Invasion and migration assays. Cell migration and invasion assays were performed using polycarbonate membrane Trans-well inserts ( $8 \mu \mathrm{m}$ pore size) in a 24 -well format (Corning, Inc., Corning, NY, USA). For the invasion assay, the insert membranes were precoated with diluted Matrigel (BD Biosciences, San Jose, CA, USA). Cells (1x10 $/$ well) in $0.2 \mathrm{ml}$ of serum-free medium were seeded onto the membranes of the upper chambers, which had been inserted into the wells containing 10\% FBS-supplemented medium. After $24 \mathrm{~h}$, the cells were fixed with $100 \%$ methanol and stained with $0.1 \%$ crystal violet. Non-invaded cells were removed from the upper well with cotton swabs. The Transwell migration assay was performed in a similar manner but without Matrigel on the filter. Cells were counted in three randomly chosen fields and photographed under an inverted microscope (magnification, x200).

shRNA-mediated FGFR2 knockdown. Lentivirus-FGFR2RNAi vector and the corresponding empty vector were obtained from Shanghai GeneChem, Co., Ltd. (Shanghai, China). Two independent shRNA constructs (target sequence: shRNA-1, 5'-CCCTGTTTGATAGAGTATA-3'; shRNA-2, 5'-GAGGCTACAAGGTACGAAA-3') were designed and subcloned into the lentivirus-FGFR2-RNAi vector to generate hU6-MCS-CMV-Puromycin, which was confirmed by Sanger sequencing. The recombinant lentiviruses were packaged and prepared at a final titer of more than $3 \times 10^{8}$ transducing units $/ \mathrm{ml}$. SGC7901 cells were cultured to $60 \%$ confluency in complete medium for $24 \mathrm{~h}$ before transduction. Lentivirus-FGFR2RNAi vectors or empty vectors were added at a multiplicity of infection of 100 and supplemented with $5 \mu \mathrm{g} / \mathrm{ml}$ polybrene (Shanghai GeneChem). The supernatant was changed after $12 \mathrm{~h}$. After culturing for another $72 \mathrm{~h}$, the stably transfected cells were selected on $2 \mu \mathrm{g} / \mathrm{ml}$ puromycin (Shanghai GeneChem) for 1 week. The expression level was examined by quantitative reverse-transcription (qRT)-PCR and western blotting at 1 week after selection.

Western blotting. Cultured cells were lysed in radioimmunoprecipitation assay lysis buffer with protease inhibitor cocktail (Roche Diagnostics, Indianapolis, IN, USA). Equal amounts of protein $(30 \mu \mathrm{g})$ solubilized in sample buffer were separated by $10 \%$ sodium dodecyl sulfate polyacrylamide gel electrophoresis and transferred onto polyvinylidene fluoride membranes (Millipore, Billerica, MA, USA). The membranes were blocked in TBS containing 0.1\% Tween-20 (TBS-T) plus $5 \%$ non-fat dried milk for $1 \mathrm{~h}$ at room temperature and probed with primary antibodies at $4^{\circ} \mathrm{C}$ overnight. Primary antibodies were used at the specified dilutions: anti-FGFR2 (11835, 1:1,000; Cell Signaling Technology), anti-phosphoFGFR (3471, 1:1,000; Cell Signaling Technology), anti-THBS1 (TA325040, 1:1,000; Origene) and anti- $\beta$-actin (66009-1-lg, 
A

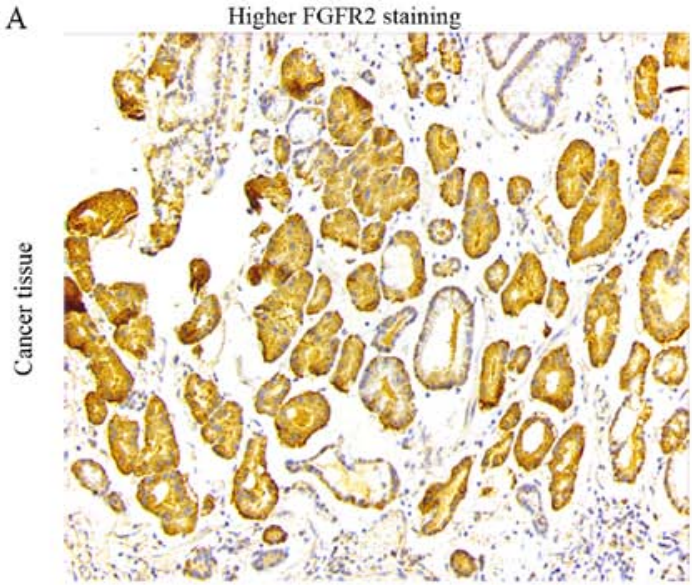

$\mathrm{C}$

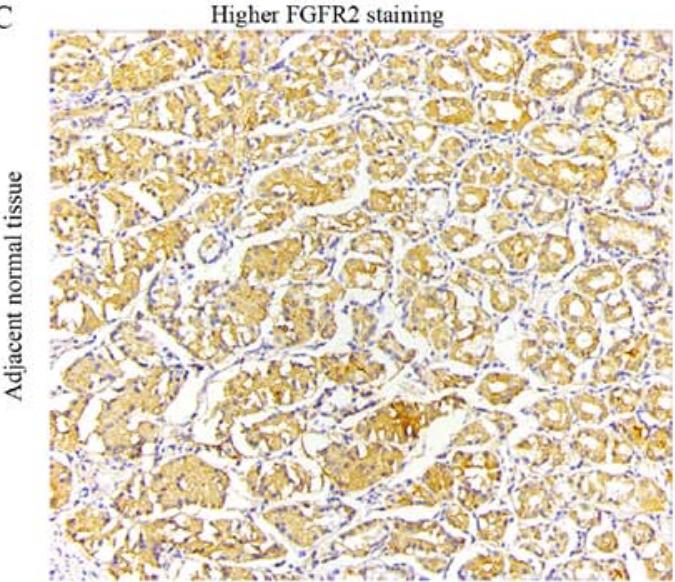

B

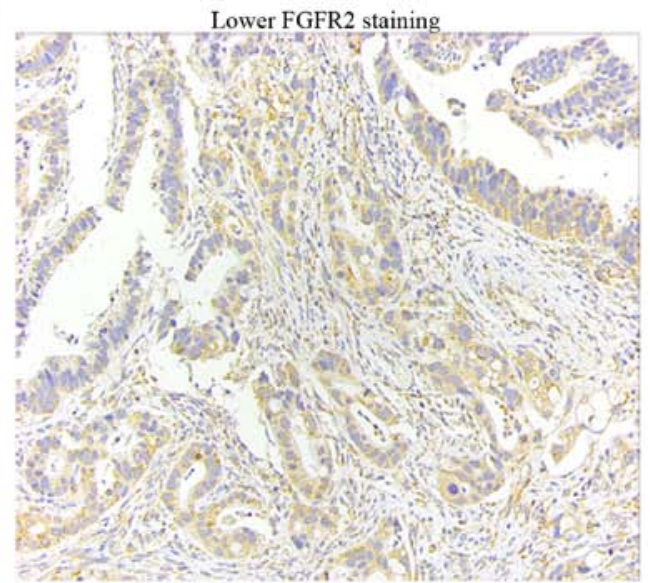

$\mathrm{D}$

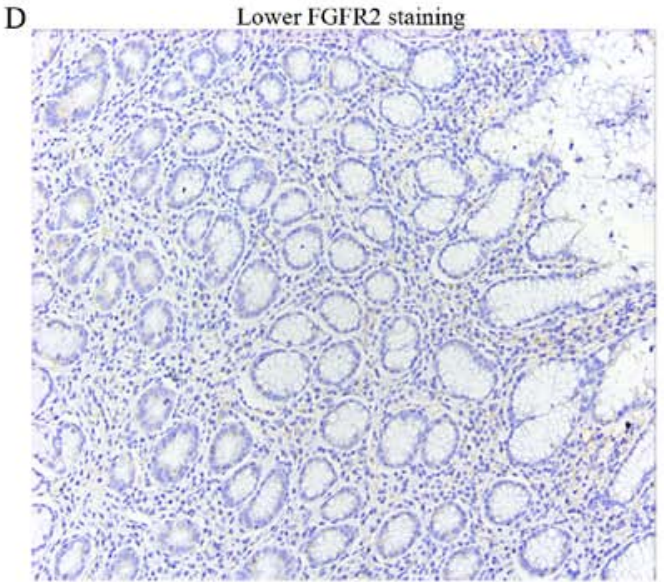

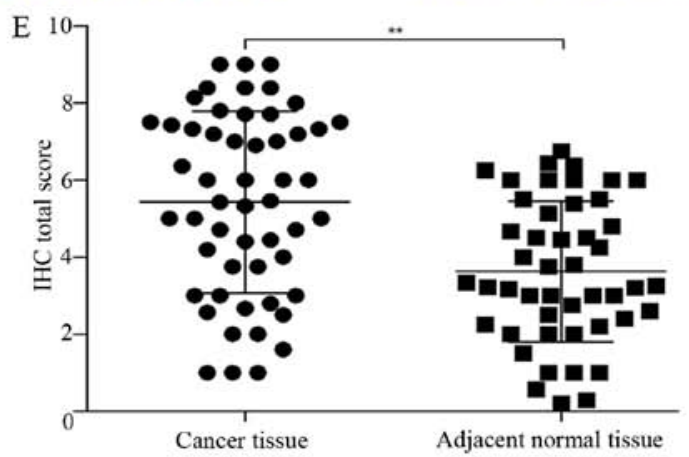

Figure 1. Expression of FGFR2 in paired tumor and adjacent normal tissues. (A-D) Representative micrographs showing higher FGFR2 staining and lower FGFR2 staining in human gastric cancer tissue (A and B) and adjacent normal tissues (C and D) (magnification, x200). (E) Quantification of FGFR2 expression in tumor tissues compared with adjacent normal tissues. Data are presented as the mean $\pm \mathrm{SD}\left({ }^{* *} \mathrm{P}<0.01\right)$.

1:5000; Proteintech, Chicago, IL, USA). The membranes were washed 3 times for 10-15 min each in TBS-T and incubated with horseradish peroxidase-conjugated goat anti-rabbit or anti-mouse secondary antibodies (SA00001-2, SA00001-1, 1:5,000; Proteintech) for $1 \mathrm{~h}$ at room temperature. Proteins were visualized using an ECL detection kit (Thermo Fisher Scientific, Waltham, MA, USA).

$q R T-P C R$. Total RNA was extracted using TRIzol reagent (TransGen Biotech, Beijing, China), and reverse transcription was carried out using the RevertAid First Strand cDNA Synthesis kit (Thermo Fisher Scientific) according to the manufacturer's instructions. For qPCR analysis, aliquots of cDNA were amplified using the Fast SYBR-Green Master Mix (Thermo Fisher Scientific) on an ABI Prism 7900 Sequence
Detector. The threshold cycle $(\mathrm{Ct})$ was measured during the exponential amplification phase, and the amplification plots were analyzed using SDS 2.1 software (Applied Biosystems, Waltham, MA, USA). The PCR program consisted of an initial denaturation cycle $\left(10 \mathrm{~min}\right.$ at $\left.95^{\circ} \mathrm{C}\right)$ followed by 40 cycles of denaturation $\left(15 \mathrm{sec}\right.$ at $\left.95^{\circ} \mathrm{C}\right)$ and annealing and elongation $\left(60 \mathrm{sec}\right.$ at $\left.60^{\circ} \mathrm{C}\right)$. A melting curve analysis was added at the end of the program. The following primers were used: FGFR2, forward, 5'-GGAAAGTGTGGTCCCATCTGA-3' and reverse 5'-TCCAGGTGGTACGTGTGATTG-3'; THBS1, forward, 5'-GCTCCAGCTCTACCAGTGTC-3' and reverse, 5'-TCAGT CACTTGCGGATGCT-5'; GAPDH, forward, 5'-GGAGCG AGATCCCTCCAAAAT-3' and reverse 5'-GGCTGTTGTCA TACTTCTCATGG-3'. GAPDH was used as an endogenous control. The relative gene expression levels were calculated 
Table I. Correlation of FGFR2 expression with clinicopathological factors.

\begin{tabular}{|c|c|c|c|c|}
\hline Parameters & No. & $\begin{array}{c}\text { Low } \\
\text { expression }\end{array}$ & $\begin{array}{c}\text { High } \\
\text { expression }\end{array}$ & P-value \\
\hline \multicolumn{5}{|l|}{ Age (years) } \\
\hline$<53$ & 27 & 8 & 19 & 0.827 \\
\hline$\geq 53$ & 26 & 7 & 19 & \\
\hline \multicolumn{5}{|l|}{ Gender } \\
\hline Male & 37 & 10 & 27 & 0.754 \\
\hline Female & 16 & 5 & 11 & \\
\hline \multicolumn{5}{|l|}{ Tumor size $(\mathrm{cm})$} \\
\hline$\leq 4$ & 29 & 10 & 19 & 0.272 \\
\hline$>4$ & 24 & 5 & 19 & \\
\hline \multicolumn{5}{|l|}{ Differentiation } \\
\hline Poor & 31 & 8 & 23 & 0.632 \\
\hline Well+moderate & 22 & 7 & 15 & \\
\hline \multicolumn{5}{|l|}{ Tumor depth } \\
\hline $\mathrm{T} 1+\mathrm{T} 2+\mathrm{T} 3$ & 16 & 8 & 8 & $0.022^{\mathrm{a}}$ \\
\hline $\mathrm{T} 4$ & 37 & 7 & 30 & \\
\hline \multicolumn{5}{|l|}{ Lymph node } \\
\hline $\mathrm{N} 0+\mathrm{N} 1$ & 28 & 9 & 19 & 0.511 \\
\hline $\mathrm{N} 2+\mathrm{N} 3$ & 25 & 6 & 19 & \\
\hline \multicolumn{5}{|l|}{ Distant metastasis } \\
\hline M0 & 53 & 15 & 38 & - \\
\hline M1 & 0 & 0 & 0 & \\
\hline \multicolumn{5}{|l|}{ Clinical stage } \\
\hline $\mathrm{I}+\mathrm{II}$ & 20 & 9 & 11 & $0.036^{\mathrm{a}}$ \\
\hline III+IV & 33 & 6 & 27 & \\
\hline
\end{tabular}

P-value was generated by Chi-square test or Fisher's exact test. ${ }^{\text {a }} \mathrm{P}<0.05$ was considered as statistically significant.

using the comparative $\mathrm{Ct}(\Delta \Delta \mathrm{Ct})$ method, where the relative expression is calculated as $2^{-\Delta \Delta C t}$.

Enzyme-linked immunosorbent assay (ELISA). Serumstarved cells were treated with or without FGF7. At 12, 24 and $48 \mathrm{~h}$, conditioned media were collected and ELISA for human THBS1 was conducted according to the manufacturer's protocol (Origene). THBS1 concentration was determined from a standard curve.

siRNA-mediated RNAi. siRNAs (THBS1, siRNA-1 5'-CGU UGGUGAUGUAACAGAATT-3', siRNA-2 5'-GAGUGGACC UCCUGUUCUATT-3', siRNA-3 5'-GCGUGAAGUGUACU AGCUATT-3') were synthesized at Shanghai GeneChem. A non-targeting siRNA (Shanghai GeneChem) was used as a negative control. Cells were transiently transfected with siRNA using Lipofectamine 2000 (Invitrogen, Waltham, MA, USA) according to the manufacturer's protocol. Briefly, siRNAs were diluted in serum-free media and mixed with Lipofectamine 2000. The mixture was left at room temperature for $10 \mathrm{~min}$. Cells were washed twice with phosphate-buffered saline (PBS)
Table II. Correlation of THBS1 expression with clinicopathological factors.

\begin{tabular}{|c|c|c|c|c|}
\hline Parameters & No. & $\begin{array}{c}\text { Low } \\
\text { expression }\end{array}$ & $\begin{array}{c}\text { High } \\
\text { expression }\end{array}$ & P-value \\
\hline \multicolumn{5}{|l|}{ Age (years) } \\
\hline$<53$ & 27 & 10 & 17 & 0.430 \\
\hline$\geq 53$ & 26 & 7 & 19 & \\
\hline \multicolumn{5}{|l|}{ Gender } \\
\hline Male & 37 & 9 & 28 & 0.066 \\
\hline Female & 16 & 8 & 8 & \\
\hline \multicolumn{5}{|l|}{ Tumor size $(\mathrm{cm})$} \\
\hline$\leq 4$ & 29 & 7 & 22 & 0.174 \\
\hline$>4$ & 24 & 10 & 14 & \\
\hline \multicolumn{5}{|l|}{ Differentiation } \\
\hline Poor & 31 & 15 & 16 & $0.003^{\mathrm{a}}$ \\
\hline Well+Moderate & 22 & 2 & 20 & \\
\hline \multicolumn{5}{|l|}{ Tumor depth } \\
\hline $\mathrm{T} 1+\mathrm{T} 2+\mathrm{T} 3$ & 16 & 3 & 13 & 0.172 \\
\hline $\mathrm{T} 4$ & 37 & 14 & 23 & \\
\hline \multicolumn{5}{|l|}{ Lymph node } \\
\hline $\mathrm{N} 0+\mathrm{N} 1$ & 28 & 7 & 21 & 0.243 \\
\hline $\mathrm{N} 2+\mathrm{N} 3$ & 25 & 10 & 15 & \\
\hline \multicolumn{5}{|l|}{ Distant metastasis } \\
\hline M0 & 53 & 17 & 36 & - \\
\hline M1 & 0 & 0 & 0 & \\
\hline \multicolumn{5}{|l|}{ Clinical stage } \\
\hline $\mathrm{I}+\mathrm{II}$ & 20 & 5 & 15 & 0.39 \\
\hline III+IV & 33 & 12 & 21 & \\
\hline
\end{tabular}

P-value was generated by Chi-square test. ${ }^{a} \mathrm{P}<0.05$ was considered as statistically significant.

and then incubated with Lipofectamine-siRNA complexes in a humidified incubator at $37^{\circ} \mathrm{C}$ with $5 \% \mathrm{CO}_{2}$ for $48 \mathrm{~h}$. Transfection efficiency was detected by qRT-PCR and western blotting.

Statistical analysis. Experiments were repeated at least three times. All data are expressed as the mean \pm standard deviation (SD). Means were compared using Student's t-test. The Chi-square test or Fisher's exact test was used to analyze the relation between FGFR2 and THBS1 expression and other clinicopathological parameters. Additionally, correlation analysis was used to determine the correlation between FGFR2 and THBS1 expression. There was a positive correlation at the correlation coefficience of $r>0$. $P<0.05$ was considered statistically significant.

\section{Results}

Expression of FGFR2 and THBS1 is increased in tumor tissues, positively correlated and correlated with clinicopathological factors. We determined the protein expression of FGFR2 and THBS1 in paired tumor and adjacent normal 
A

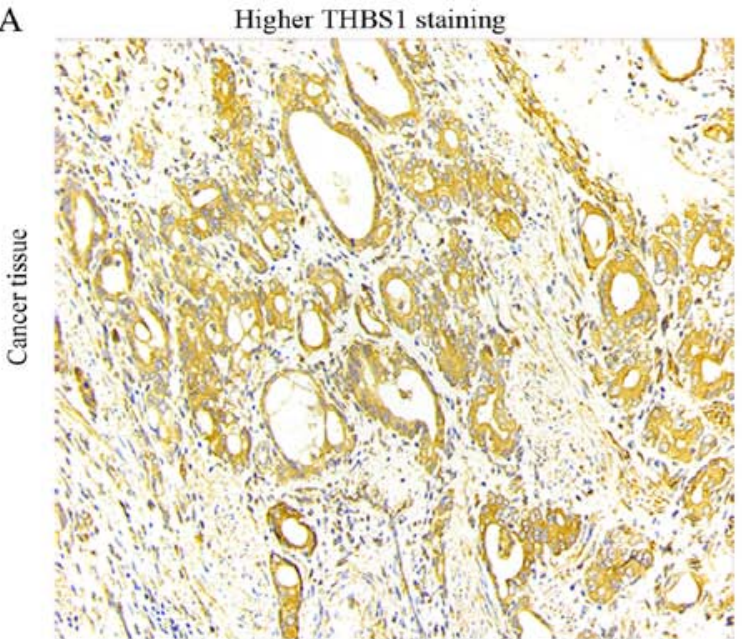

$\mathrm{C}$
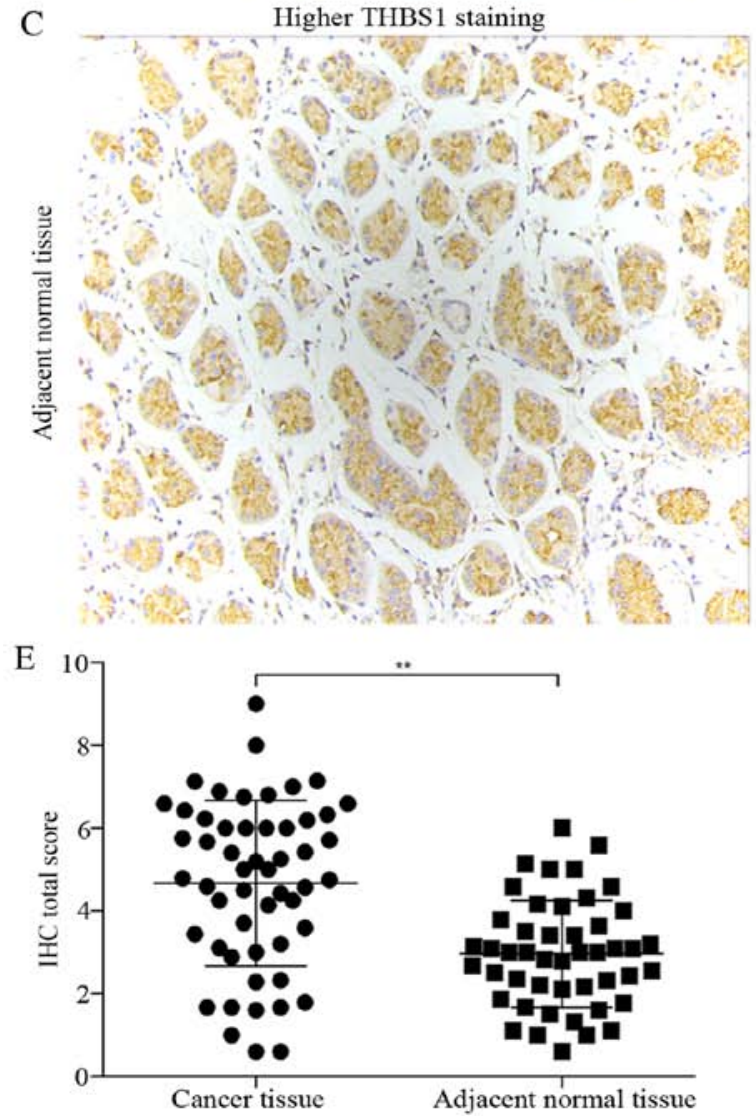

B

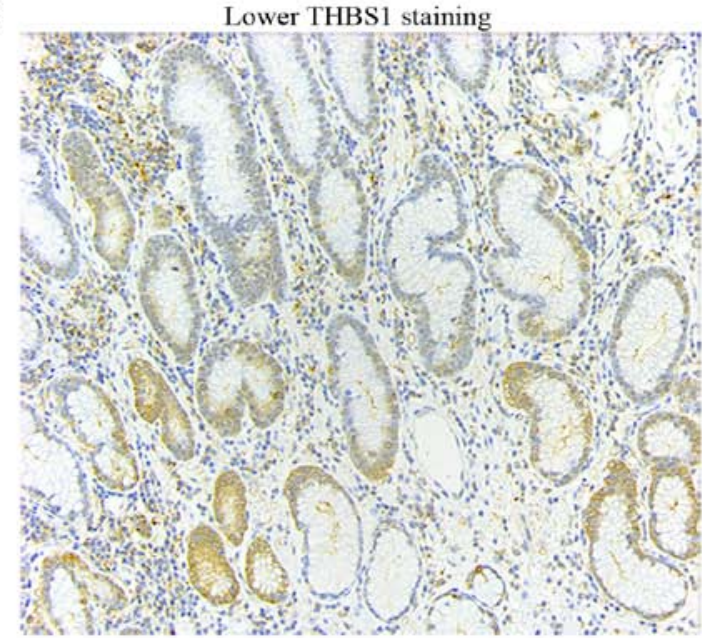

$\mathrm{D}$

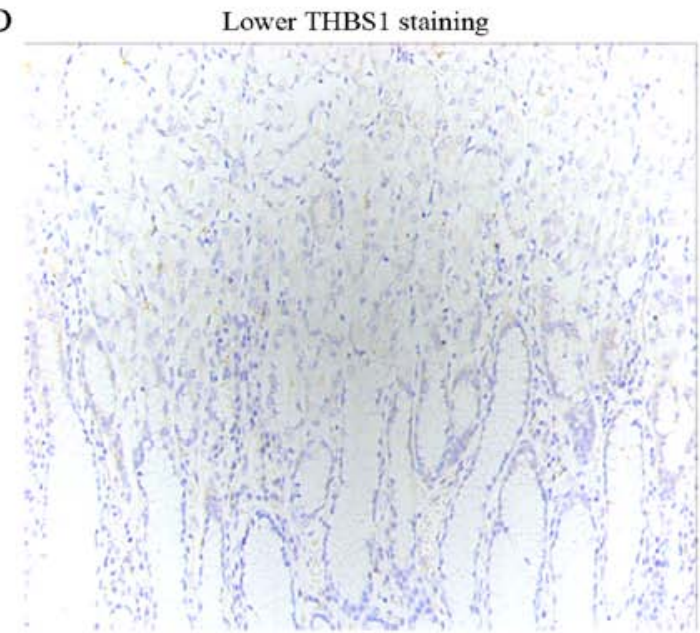

$\mathrm{F}$

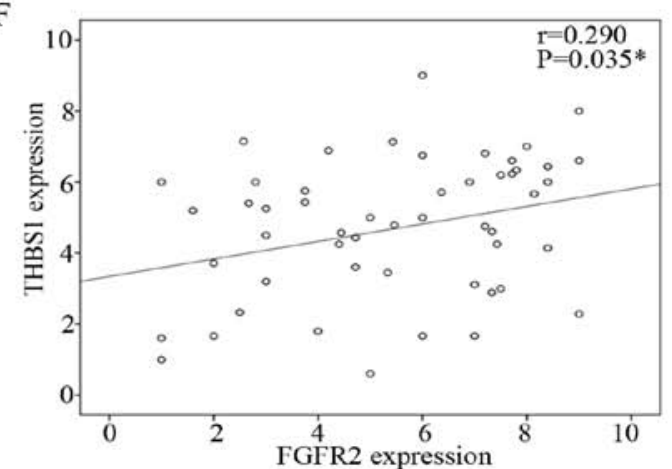

Figure 2. Expression of THBS1 in paired tumor and adjacent normal tissues, and correlation analysis between FGFR2 and THBS1 expression. (A-D) Representative micrographs showing higher THBS1 staining and lower THBS1 staining in human gastric cancer tissue (A and B) and adjacent normal tissues (C and D) (magnification, x200). (E) Quantification of THBS1 expression in tumor tissues compared with adjacent normal tissues. Data are presented as the mean $\pm \mathrm{SD}\left({ }^{* *} \mathrm{P}<0.01\right)$. (F) Correlation analysis of FGFR2 and THBS1 expression.

tissues of 53 patients undergoing curative resection by IHC. FGFR2 was mainly expressed in the cytoplasm (Fig. 1A and C), while THBS1 was expressed in the cytoplasm and extracellular matrix (Fig. 2A and C). Compared with adjacent normal tissues, tumor tissues had significantly elevated expression of FGFR2 and THBS1 (Figs. 1E and 2E).

Next, we classified the cancer tissues into high and lowexpression groups according to the criteria described in Materials and methods. With the aim to identify the parameters affecting processes involving FGFR2 and THBS1 in gastric cancer, we analyzed the correlations between FGFR2 and
THBS1 expression and those with clinicopathological factors using the Chi-square test or Fisher's exact test. Correlation analysis suggested a positive correlation between FGFR2 and THBS1 expression ( $\mathrm{r}=0.29, \mathrm{P}=0.035)$ (Fig. $2 \mathrm{~F})$. The median age at the time of diagnosis was 53 years (range, 27-81 years). Patients with high FGFR2 expression had deeper tumor depth $(\mathrm{P}=0.021)$ and were in a later clinical stage $(\mathrm{P}=0.036)$ than patients with low FGFR2 expression (Table I). However, high expression of THBS1 was correlated with well and moderate tumor differentiation $(\mathrm{P}=0.003)$ (Table II). These findings indicated that high FGFR2 expression may promote 
A

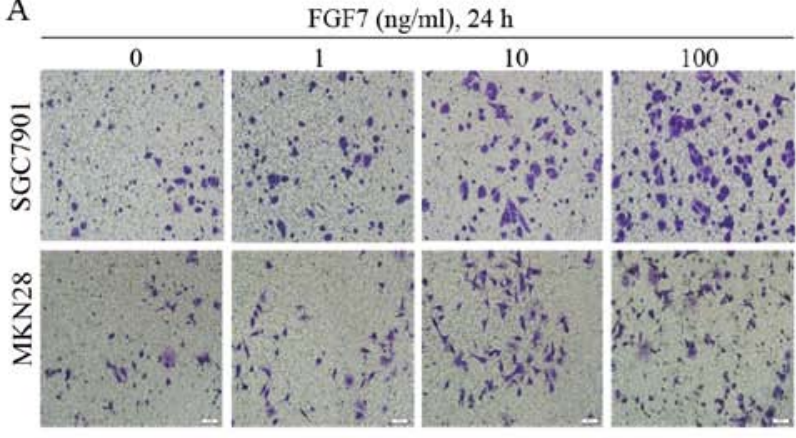

C
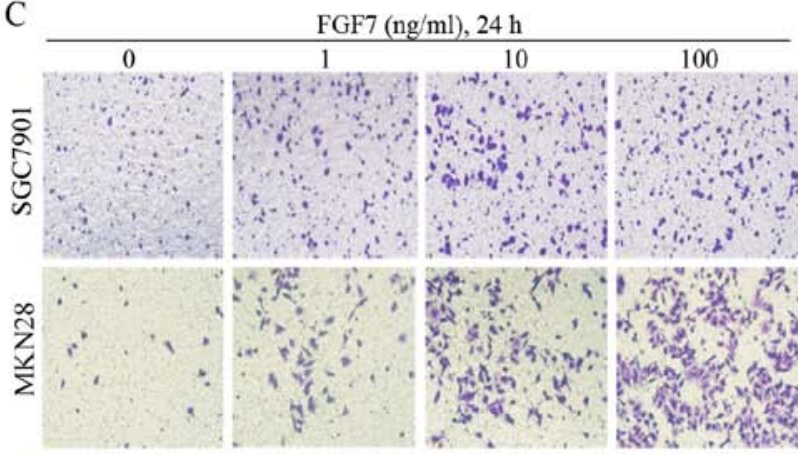

E

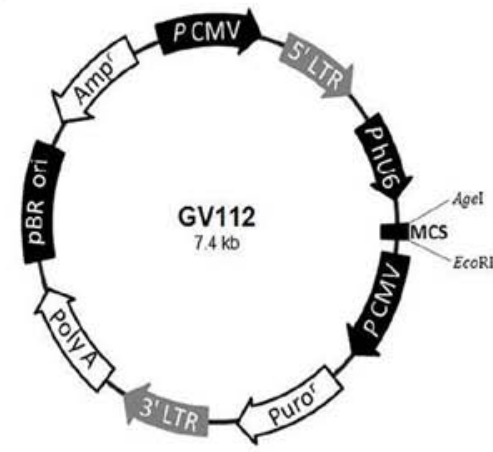

$\mathrm{H}$
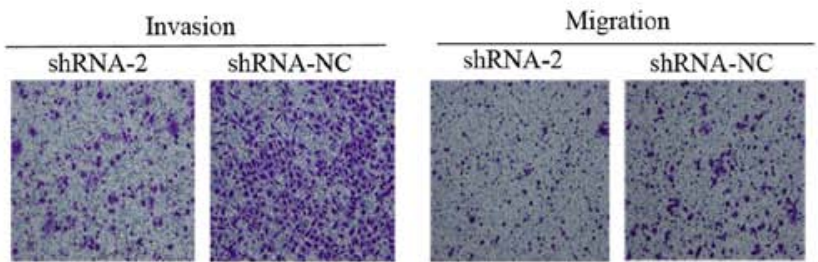

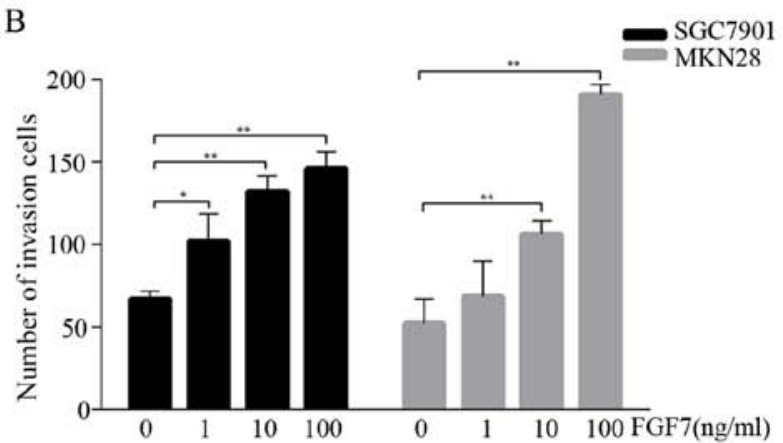

D

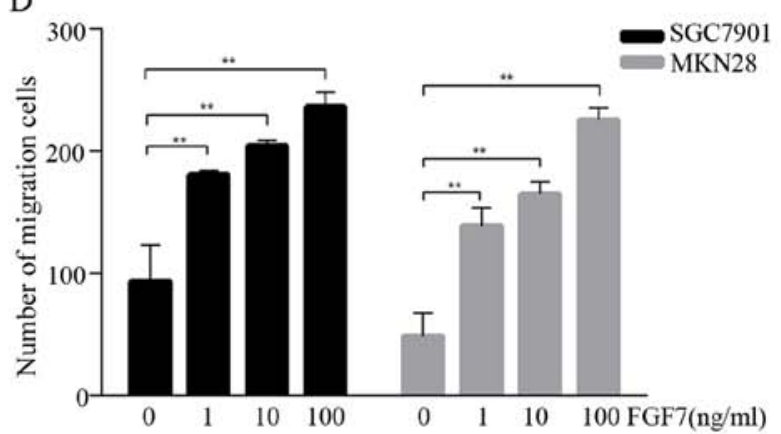

G

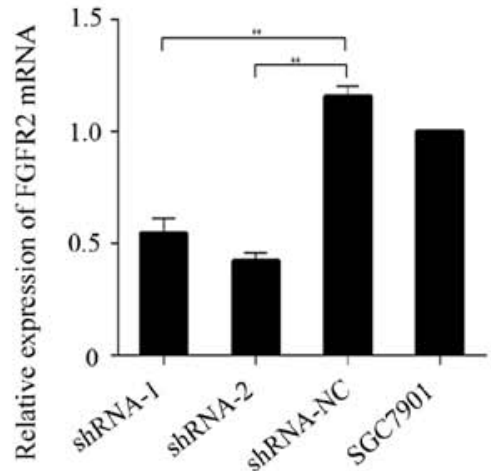

I

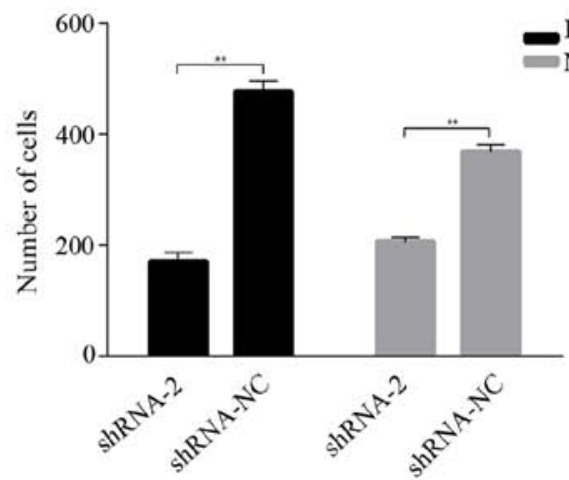

Figure 3. FGF7 promotes invasion and migration in human gastric cancer cells. (A-D) Invasion and migration assays showed the effect of FGF7 on invasion and migration in SGC7901 and MKN28 cells. The cells were photographed under an inverted microscope (magnification, x200) (A and C). Number of cells was counted in three randomly chosen fields (B and D). (E) Schematic representation of the lentiviral vector used in transfection. (F) Western blot analysis for FGFR2 in transfected cells and SGC7901. (G) The relative expression of FGFR2 mRNA in transfected cells and SGC7901 as detected by qRT-PCR. ( $\mathrm{H}$ and I) Cell invasion and migration assays of shRNA-2 and shRNA-NC transfected cells treated with FGF7 (10 ng/ml, 24 h). Data are presented as the mean $\pm \mathrm{SD}$ of three independent experiments $\left({ }^{* *} \mathrm{P}<0.01\right)$.

the invasion and migration in gastric cancer, and THBS1 is a multifunctional protein that exerts important roles on tumor progression.

FGF7/FGFR2 promotes invasion and migration in human gastric cancer cells. To mimic paracrine regulation and to check whether exogenous FGF7 would promote invasion and migration in vitro, we conducted invasion and migration assays using SGC7901 and MKN28 cells and different concentrations $(1,10$ and $100 \mathrm{ng} / \mathrm{ml})$ of FGF7. The treatment with FGF7 caused a dose-dependent increase in the number of invading (Fig. 3A and B) and migrating (Fig. 3C and D) cells. To study 
A

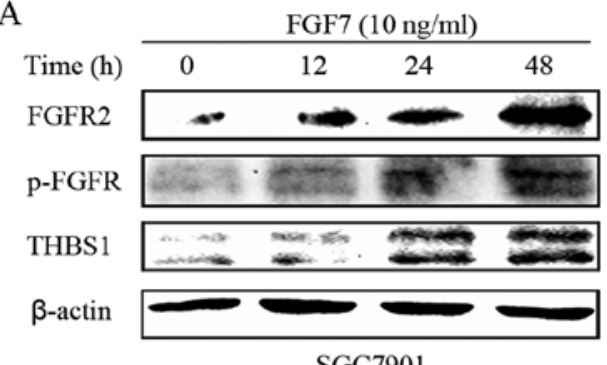

SGC7901

C

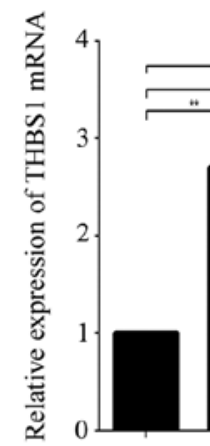

FGF7(10 ng/ml) 0 (a)

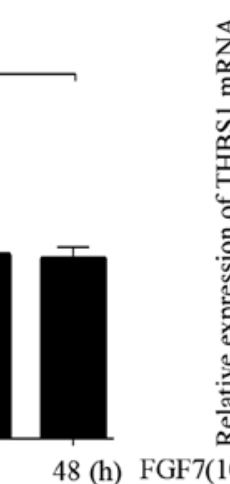

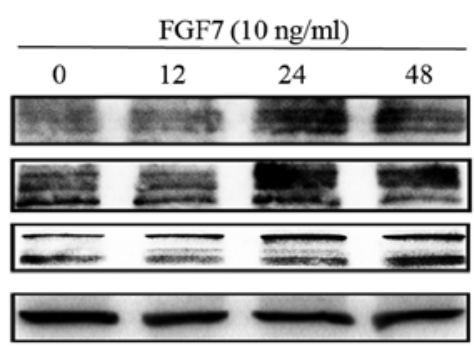

MKN28

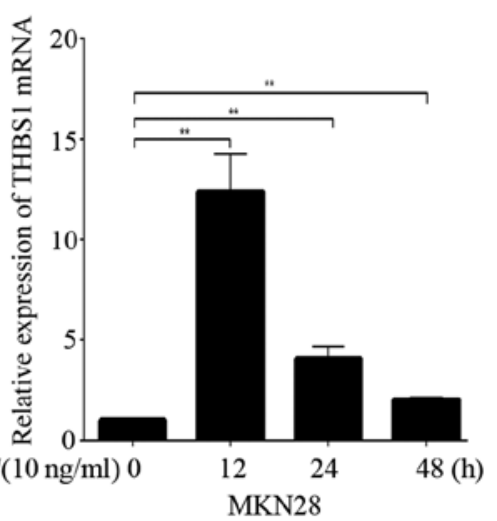

B

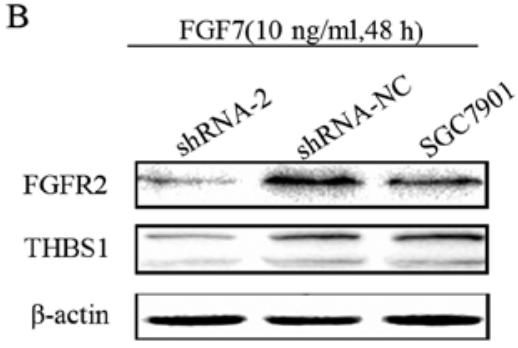

D

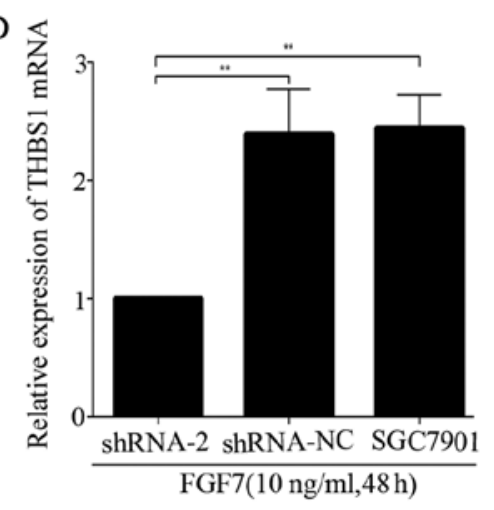

E

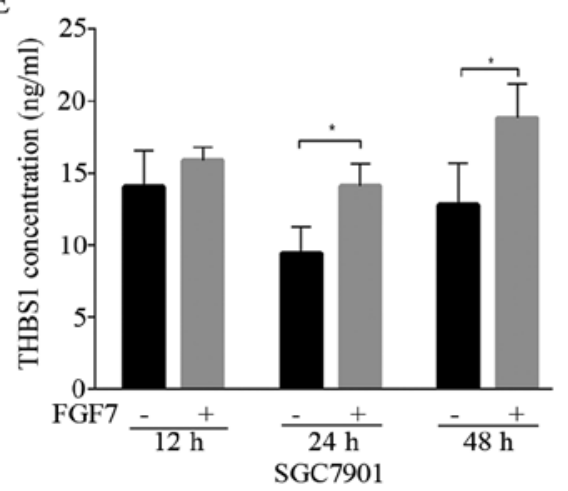

F

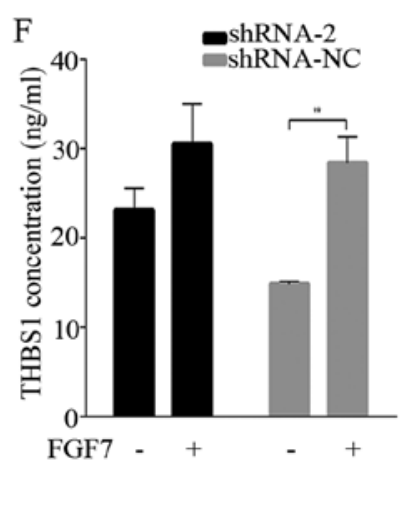

Figure 4. FGF7 elevates the expression of THBS1 in vitro. (A-D) Cells were incubated with FGF7 (10 ng/ml) for the indicated times. The expression of FGFR2, p-FGFR, THBS1 was detected by western blotting (A). The relative expression of THBS1 mRNA was detected by qRT-PCR (C). FGFR2 and THBS1 expression (B) and relative expression of THBS1 mRNA (D) were detected after treatment with FGF7 (10 ng/ml for 48 h) in shRNA-2 and shRNA-NC transfected cells and SGC7901 cells. (E) THBS1 secreted by cells treated with or without FGF7 for 12, 24 and $48 \mathrm{~h}$ was determined by ELISA. (F) THBS1 in the condition media of shRNA-2 and shRNA-NC transfected cells treated with or without FGF7 was detected by ELISA. Data are presented as the mean \pm SD of three independent experiments $\left({ }^{*} \mathrm{P}<0.05,{ }^{* *} \mathrm{P}<0.01\right)$.

FGF7 function further, we knocked down FGFR2 expression in SGC7901 cells via lentivirus-mediated shRNA transduction. Two independent shRNAs (shRNA-1 and shRNA-2) and a negative control shRNA (shRNA-NC) were subcloned into the vector GV112 (Fig. 3E). After lentiviral transduction was stabilized, FGFR2 expression was verified both at the protein and the mRNA level. Western blotting showed that the protein expression in the shRNA-2 cells was significantly suppressed (Fig. 3F) and the mRNA level in the shRNA-2 cells was $>50 \%$ lower than shRNA-NC cells (Fig. 3G). The shRNA-1 was not as effective as shRNA-2 in the knockdown of FGFR2. FGFR2 protein and mRNA expression was similar between shRNA-NC and normal SGC7901 cells (Fig. 3F and G). FGF7 treatment (10 $\mathrm{ng} / \mathrm{ml}$ for $24 \mathrm{~h}$ ) elevated the invasive and migratory abilities of shRNA-NC cells compared to shRNA-2 cells (Fig. 3H and I). Thus, FGF7/FGFR2 is involved in the invasion and migration of human gastric cancer cells.
THBS1 is required for the effect of FGF7/FGFR2 on invasion and migration in gastric cancer cells. Next, we investigated the relation of FGF7/FGFR2 and THBS1 in vitro. FGF7 treatment elevated the expression of FGFR2, p-FGFR and THBS1 in both SGC7901 and MKN28 gastric cancer cells in a timedependent manner (Fig. 4A). THBS1 mRNA expression was also elevated after FGF7 treatment in both gastric cancer cells (Fig. 4C). Based on this observation, we sought to confirm the potential relation between FGF7/FGFR2 and THBS1, using the FGFR2 knockdown SGC7901 cells. The shRNA-2 hairpin potently inhibited THBS1 upon treatment with FGF7 (10 ng/ $\mathrm{ml}$ for $48 \mathrm{~h}$ ), while shRNA-NC did not decrease the THBS1 protein and mRNA level (Fig. 4B and D). It has been previously noted that THBS1 in the extracellular matrix modulates tumor progress and metastasis, therefore, we evaluted THBS1 secretion by ELISA. SGC7901 and MKN28 cells were exposed to FGF7 (10 ng/ml) and incubated for 12,24 or $48 \mathrm{~h}$. The level 
A

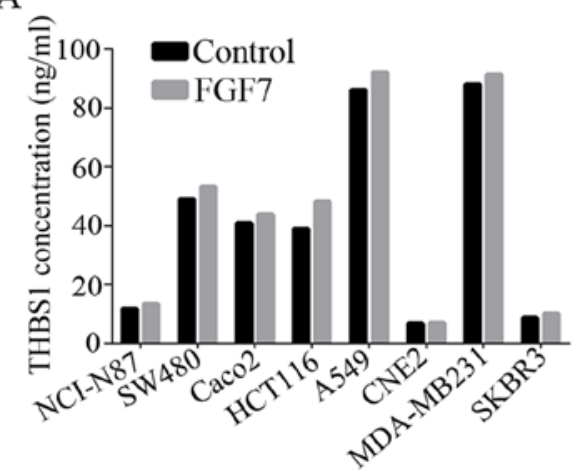

D

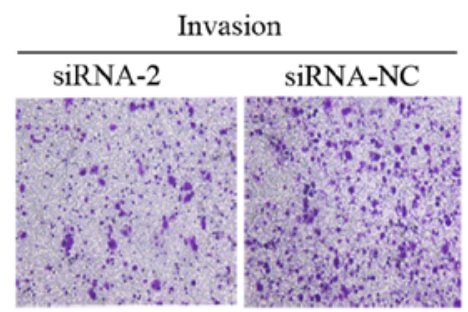

B

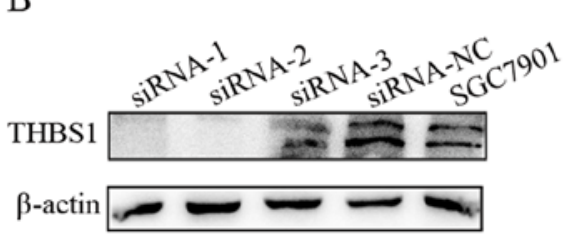

$\mathrm{C}$

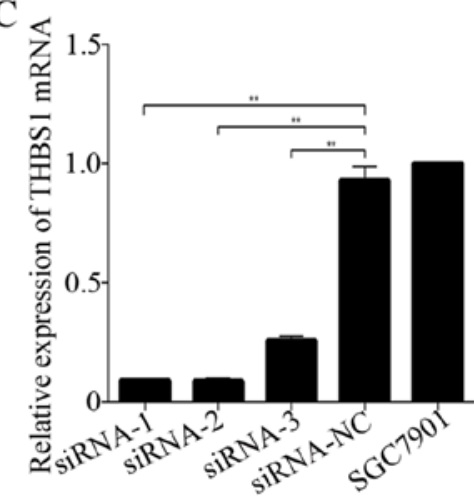

E
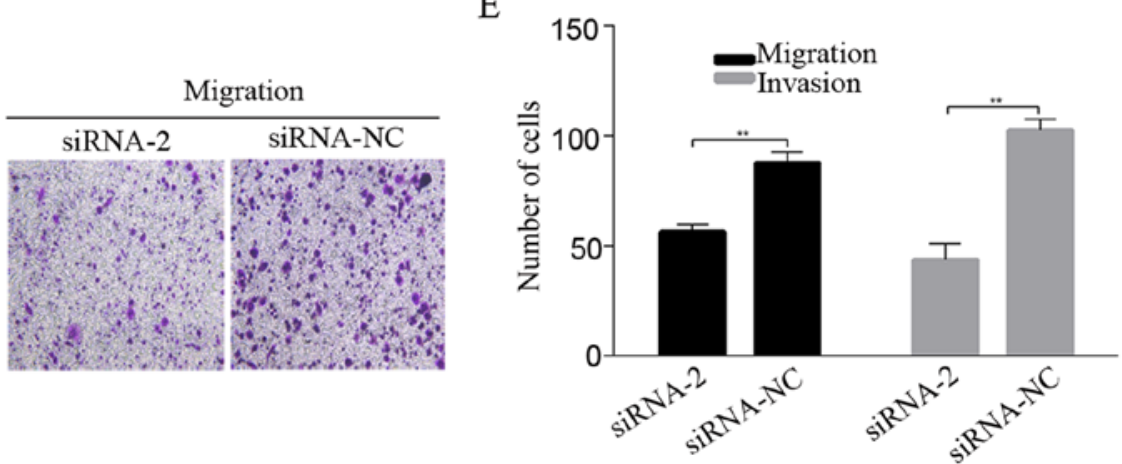

Figure 5. THBS1 is required for the effect of FGF7 on invasion and migration in gastric cancer cells. (A) Cancer cell lines were treated with or without FGF7, THBS1 in the condition media were detected by ELISA. Western blotting (B) and qRT-PCR (C) were used to evaluate the efficiency of THBS1 knockdown in SGC7901 cells transfected with siRNA-1, siRNA-2, siRNA-3 and siRNA-NC. (D and E) Cells transfected with siRNA-2 and siRNA-NC were treated with FGF7 (10 ng/ml) and subjected to invasion and migration assays. Data are presented as the mean $\pm \mathrm{SD}$ of three independent experiments $\left({ }^{* *} \mathrm{P}<0.01\right)$.

of FGF7-enhanced THBS1 secretion increased significantly after $24 \mathrm{~h}$ of stimulation in SGC7901 cells, while MKN28 cells showed a slight, but statistically insignificant increase in secretion (Fig. 4E). THBS1 in the conditioned media of shRNA-NC transfected SGC7901 cells was significantly increased after treatment with FGF7, while no significant alternation was observed in FGFR2 shRNA-2 transfected cells (Fig. 4F). Similarly, FGF7 enhanced the secretion of THBS1 in most other cell lines derived from cancers of various locations except CNE2 (Fig. 5A).

To define the role of THBS1 in FGF7-induced invasion and migration, we knocked down THBS1 expression in SGC7901 cells using siRNA and Lipofectamine 2000. The knockdown proved succesful (Fig. 5B and C). Invasion and migration assays revealed that knowdown of THBS1 inhibited FGF7induced invasion and migration (Fig. 5D and E), indicating that THBS1 is required for the effect of FGF7 on invasion and migration in gastric cancer cells.

FGF7 regulates THBS1 through PI3K/Akt/mTOR pathway in vitro. Because FGF7/FGFR2 upregulated THBS1, we aimed to elucidate the underlying molecular mechanisms by using several small-molecular inhibitors, including LY294002 (PI3K inhibitor), U0126 (MEK inhibitor), SB203580 (p38 MAPK inhibitor) and SP600125 (JNK inhibitor). After pretreatment of the cells with FGF7, we examined the level of THBS1 in the presence of small-molecular inhibitors by western blotting at different time-points. We observed inhibition of THBS1 after treatment with LY294002 in both SGC7901 and MKN28 cells (Fig. 6A). However, other inhibitors did not decrease
THBS1 expression in either cell line. These results suggested that FGF7/FGFR2 modulated THBS1 mainly through the PI3K pathway. Furthermore, we examined whether mTOR participates in the modulation. As shown in Fig. 6B and $\mathrm{C}$, the mTOR inhibitor RAD001 significiantly inhibited THBS1 protein and mRNA expression in SGC7901 and MKN28 cells. Thus, FGF7 upregulates THBS1 through the PI3K/Akt/mTOR pathway in vitro.

\section{Discussion}

Overexpression of FGFR2 has been reported in various cancers including lung, pancreatic and breast cancers (26-28), and FGFR2 has been suggested as a novel therapeutic target $(29,30)$. While increased expression of FGFR2 in gastric cancer has been reported $(31,32)$, its role is not clear. To elucidate its role in gastric cancer, we examined FGFR2 expression in human gastric cancer tissues. FGFR2 was generally overexpressed in cancer vs. adjacent normal tissues. Especially, FGFR2 was highly expressed in T4 or stage III and IV patients, and its increased expression tended to correlate with invasion and migration. The 5-year survival rates for stage I and II patients exceeded $60 \%$, while the rates for stage III and IV patients rarely exceeded 50\% (33). Despite many advances in diagnosis and treatment of this disease, the prognosis for gastric cancer remains poor, especially in more advanced stages. Therefore, we evaluated two groups of clinical stage of gastric cancer together (stage I together with stage II and stage III together with stage IV). Similarly, FGFR2 expression significantly associated with tumor depth and survival of patients in 
A
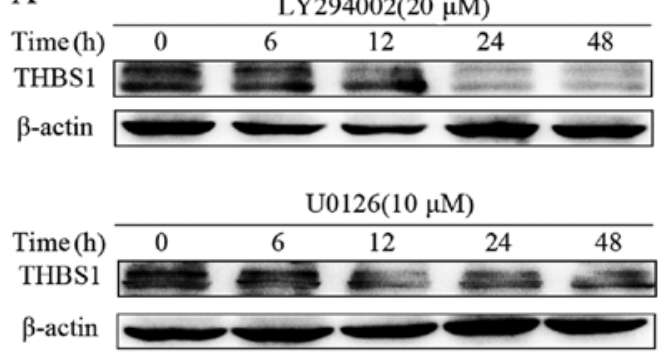

SB203580 $(10 \mu \mathrm{M})$
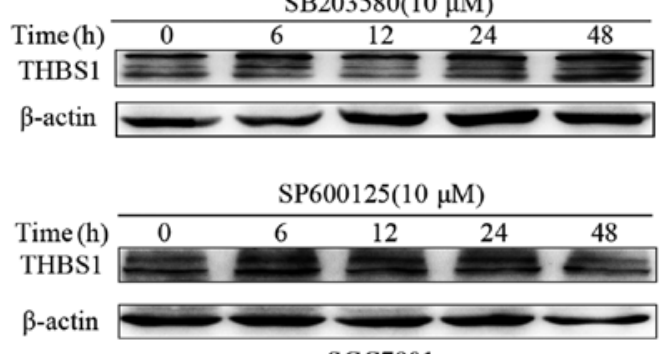

SGC7901

B

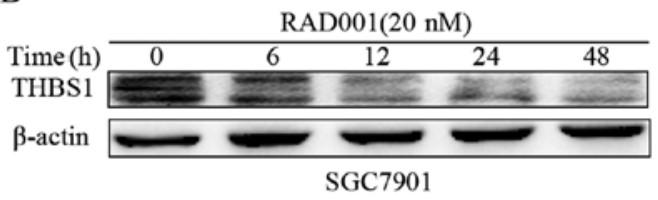

C

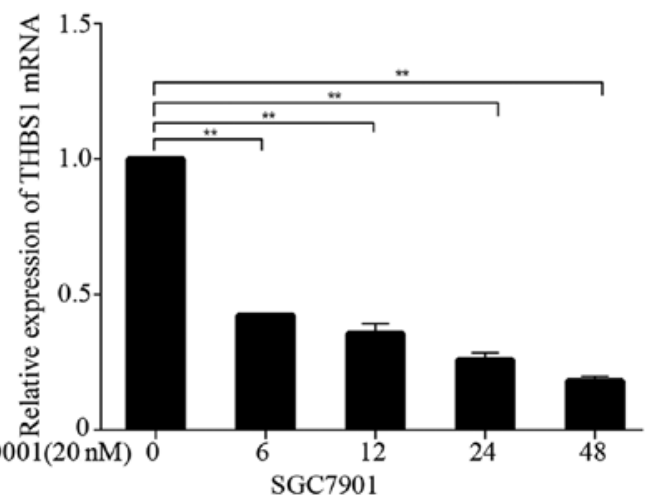

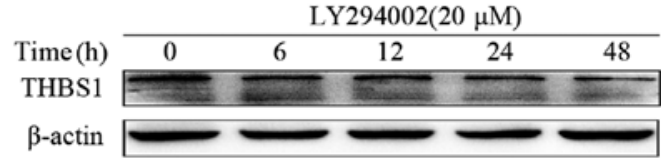

U0126(10 $\mu \mathrm{M})$

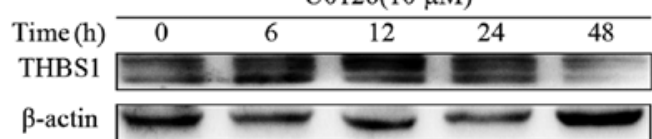

$\operatorname{SB} 203580(10 \mu \mathrm{M})$
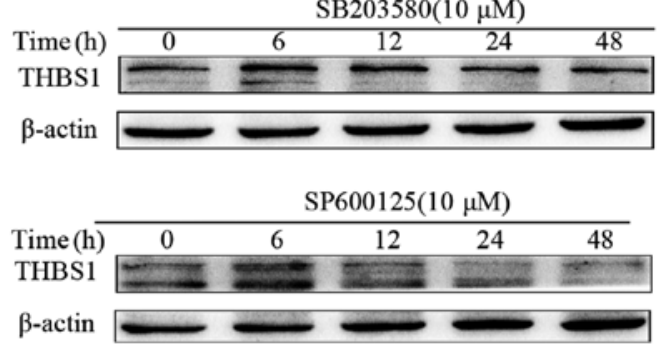

MKN28
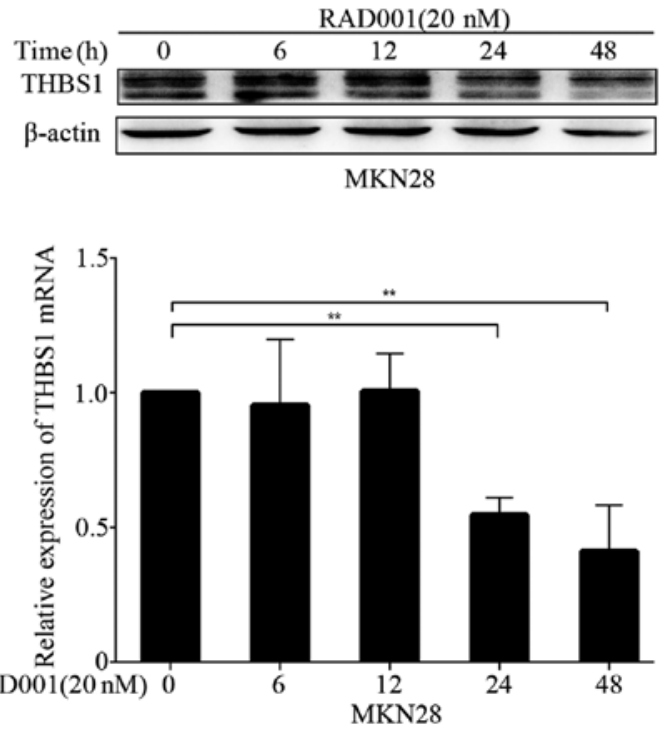

Figure 6. FGF7 regulates THBS1 through PI3K/Akt/mTOR pathway in vitro. (A and B) Cells were pretreated with FGF7 (10 ng/ml for 48 h), and THBS1 was assessed by performing western blotting after treated with indicated concentration of LY294002, U0126, SB203580, SP600125 (A) and RAD001 (B) at different time-points. (C) Relative expression of THBS1 mRNA in cells treated with RAD001 (pretreated with FGF7) was assessed by qRT-PCR. Data are presented as the mean $\pm \mathrm{SD}$ of three independent experiments $\left({ }^{* *} \mathrm{P}<0.01\right)$.

esophagogastric junction adenocarcinoma (34). The study by Nakazawa et al (35) suggested that gastric fibroblast expressed FGF7, whereas gastric cancer cells did not and FGFR2 was expressed in gastric cancer cells, while not expressed in fibroblast, indicating that FGF7 stimulated proliferation of gastric cancer cells in a paracrine manner. In gastric cancer cell lines, we found that administration of FGF7, the ligand of FGFR2, induced cell invasion and migration, while FGFR2 shRNA-2transfected cells treated with FGF7 showed a decrease in invasion and migration. These lines of evidence suggest that FGF7/FGFR2 plays an important role in invasion and migration of gastric cancer. These data are consistent with previous reporting of FGFR2 as a candidate therapeutic target (36).

THBS1 is a multifunctional protein that exerts a variety of biological activities. Immunohistochemimcal staining for THBS1 was detected both in the cytoplasm of the gastric cancer cells and the stromal tissue. It has been reported that THBS1 was expressed in the cytoplasm of the tumor cells of the thyroid, breast and colorectal carcinoma (37-39). Whereas, there were some reports indicating that THBS1 only expressed in the stromal tissues of certain cancers including bladder, pancreas and prostate cancer (40-42). Lin et al (43) revealed that THBS1 was mainly located in stromal myofibroblasts in gastric carcinoma tissues. While Nakao et al (44) found positive staining for THBS1 in the cytoplasm of the gastric cancer cells. Weak staining of THBS1 was occasionally detected in the stromal tissues in the study by Zhang et al (45). Therefore, pattern of THBS1 expression in cancer may depend on organs or histological types, differences in the populations studied and the antibodies used in the studies. Although the role of THBS1 in angiogenesis is well documented, its role in tumor metastasis 
is only just emerging. THBS1 expression and secretion was elevated in melanoma cells and was associated with epithelialto-mesenchymal transition (20). A study showed that THBS1 was inversely correlated with the degree of invasion in papillary thyroid carcinoma (37), while other studies reported that THBS1 was a potent stimulator of cell migration and invasion in prostate, colon and breast cancers (46-48). In addition, increased primary tumor growth and decreased metastases were observed in THBS1-knockdown animal model of breast cancer (49). Thus, the role of THBS1 in cancer cell invasion and migration have yielded mixed results.

Our data demonstrated a marked overexpression of THBS1 in gastric cancer tissues when compared to adjacent normal tissues. Nevertheless, THBS1 was correlated with well and moderate tumor differentiation and this is clearly a less aggressive tumor biology. THBS1 in tumor microenvironment modulates angiogenesis, adhesion, proliferation, invasion, migration and immunity. The pleiotropic nature of THBS1 depends on the environment conditions, and the presence of its different receptors may have different, even opposite, effects on cell behavior and biological process. This result was a comprehensive effect of THBS1 and needed more patient samples and survival analysis. Thus, the effect of THBS1 on gastric cancer progression needs further investigation.

Researchers have found that there exists a relationship between FGF family and THBS1. In the study by Yu et al (50), they demonstrated that THBS1-derived molecules inhibited FGF2-stimulated angiogenesis. Taraboletti et al (51) concluded the FGF2-binding sequence of THBS1 served as a template for the development of non-peptide inhibitors of angiogenesis. Expression of THBS1 is upregulated in response to various cytokines and growth factors including platelet-derived growth factor, epidermal growth factor but downregulated in response to interleukin-1 $\beta$, tumor necrosis factor $\kappa$, interleukin- 6 and bFGF $(52,53)$. During prostate cancer progression, production of THBS1 was downregulated, while FGF2 was rised (54). FGF8-activated signaling pathways mediated THBS1 repression in breast cancer cells (55). Based on these observations, the exact role of THBS1, in particular after FGF7 binding of FGFR2 in gastric cancer, remains unclear. The present study demonstrated that THBS1 expression was positively correlated with FGFR2 expression. Moreover, FGF7 promoted THBS1 expression in vitro, and enhanced the secretion of THBS1 in most cell lines derived from cancers of various locations except MKN28 and CNE2, which needs further investigation. Knowdown of THBS1 inhibited FGF7-stimulated increase in invasion and migration. Together, these findings suggested that FGF7/FGFR2 may promote gastric cancer cell invasion and migration through a THBS1-mediated pathway.

FGF binding to their FGFRs activates multiple transduction pathways. Thus, we next screened which signaling pathway is involved in FGF7/FGFR2-driven regulation of THBS1 expression. The key pathways in FGF signaling are the RAS-MAP kinase pathway which includes ERK1/2, p38 and JNK kinase and the PI3K-Akt pathway (56). Using a series of inhibitors, we were able to demonstrate that FGF7/FGFR2-mediated upregulation of THBS1 may occur through the PI3K/Akt/ mTOR pathway. Further studies are warranted to elucidate the detailed mechanism.
Activation of FGFR2 signal pathway is related to disease progression in gastric cancer, thus, FGFR2-targeted therapy is considered promising. Unfortunately, the multi-targeted tyrosine kinase inhibitors (TKIs) with FGFR inhibitory activity has not been demonstrated superior to standard chemotherapy in most phase III clinical trials. FGF7/FGFR2related signaling cascades play important roles in gastric cancer progression through diverse mechnisms, thus, FGFR2 regulates different pathways in different gastric cancer cells. The identification of biomarkers of FGFR2-based therapy can help to choose the right patient population in personalized therapy. The combination of FGFR2 inhibitors and other agents may deliver better responses to gastric cancer patients (57). Here, we hypothesize that FGFR2 inhibitors combined with THBS1 inhibitors or mTOR inhibitors may benefit gastric cancer patients. Continued basic research is needed to gain more insights into the FGFR2 signal pathway in tumor progression.

The present study has limited sample size and lack of stage IV patients. Further investigations, such as survival analysis, the expression of FGF7 in gastric cancer patients and relevant animal experiments, are necessary to clarify the role of FGF7/FGFR2/THBS1 signal in gastric cancer progression.

In conclusion, our results demonstrated that FGF7/FGFR2 signal promotes invasion and migration in human gastric cancer through the upregulation of thrombospondin 1 . To the best of our knowledge, this is the first study to characterize the relationship of FGF7/FGFR2 and THBS1 in gastric cancer, which is significantly associated with poor prognosis by promoting invasion and migration. Our findings support further study of the FGF7/FGFG2/THBS1 as a potential target for gastric cancer.

\section{Acknowledgements}

The present study was supported by the National Natural Science Foundation of China (grants nos. 81372664 and 81372434).

\section{References}

1. Torre LA, Bray F, Siegel RL, Ferlay J, Lortet-Tieulent J and Jemal A: Global cancer statistics, 2012. CA Cancer J Clin 65: 87-108, 2015

2. Sakuramoto S, Sasako M, Yamaguchi T, Kinoshita T, Fujii M, Nashimoto A, Furukawa H, Nakajima T, Ohashi Y, Imamura H, et al; ACTS-GC Group: Adjuvant chemotherapy for gastric cancer with S-1, an oral fluoropyrimidine. N Engl J Med 357: 1810-1820, 2007.

3. Macdonald JS, Smalley SR, Benedetti J, Hundahl SA, Estes NC, Stemmermann GN, Haller DG, Ajani JA, Gunderson LL, Jessup JM, et al: Chemoradiotherapy after surgery compared with surgery alone for adenocarcinoma of the stomach or gastroesophageal junction. N Engl J Med 345: 725-730, 2001.

4. Cunningham D, Allum WH, Stenning SP, Thompson JN, Van de Velde CJ, Nicolson M, Scarffe JH, Lofts FJ, Falk SJ, Iveson TJ, et al; MAGIC Trial Participants: Perioperative chemotherapy versus surgery alone for resectable gastroesophageal cancer. N Engl J Med 355: 11-20, 2006.

5. Power DG, Kelsen DP and Shah MA: Advanced gastric cancer-slow but steady progress. Cancer Treat Rev 36: 384-392, 2010.

6. Thrumurthy SG, Chaudry MA, Chau I and Allum W: Does surgery have a role in managing incurable gastric cancer? Nat Rev Clin Oncol 12: 676-682, 2015.

7. Beenken A and Mohammadi M: The FGF family: Biology, pathophysiology and therapy. Nat Rev Drug Discov 8: 235-253, 2009. 
8. Knights V and Cook SJ: De-regulated FGF receptors as therapeutic targets in cancer. Pharmacol Ther 125: 105-117, 2010.

9. Finch PW, Rubin JS, Miki T, Ron D and Aaronson SA: Human KGF is FGF-related with properties of a paracrine effector of epithelial cell growth. Science 245: 752-755, 1989.

10. Grose R and Dickson C: Fibroblast growth factor signaling in tumorigenesis. Cytokine Growth Factor Rev 16: 179-186, 2005.

11. Yamayoshi T, Nagayasu T, Matsumoto K, Abo T, Hishikawa Y and Koji T: Expression of keratinocyte growth factor/fibroblast growth factor-7 and its receptor in human lung cancer: Correlation with tumour proliferative activity and patient prognosis. J Pathol 204: 110-118, 2004.

12. Toyokawa T, Yashiro M and Hirakawa K: Co-expression of keratinocyte growth factor and $\mathrm{K}$-sam is an independent prognostic factor in gastric carcinoma. Oncol Rep 21: 875-880, 2009.

13. Cho K, Ishiwata T, Uchida E, Nakazawa N, Korc M, Naito Z and Tajiri T: Enhanced expression of keratinocyte growth factor and its receptor correlates with venous invasion in pancreatic cancer. Am J Pathol 170: 1964-1974, 2007.

14. Zhang Y, Wang H, Toratani S, Sato JD, Kan M, McKeehan WL and Okamoto T: Growth inhibition by keratinocyte growth factor receptor of human salivary adenocarcinoma cells through induction of differentiation and apoptosis. Proc Natl Acad Sci USA 98: 11336-11340, 2001.

15. Ricol D, Cappellen D, El Marjou A, Gil-Diez-de-Medina S, Girault JM, Yoshida T, Ferry G, Tucker G, Poupon MF, Chopin D, et al: Tumour suppressive properties of fibroblast growth factor receptor 2-IIIb in human bladder cancer. Oncogene 18: 7234-7243, 1999.

16. Diez de Medina SG, Chopin D, El Marjou A, Delouvée A, LaRochelle WJ, Hoznek A, Abbou C, Aaronson SA, Thiery JP and Radvanyi F: Decreased expression of keratinocyte growth factor receptor in a subset of human transitional cell bladder carcinomas. Oncogene 14: 323-330, 1997.

17. Carlson CB, Lawler J and Mosher DF: Structures of thrombospondins. Cell Mol Life Sci 65: 672-686, 2008.

18. Baenziger NL, Brodie GN and Majerus PW: A thrombin-sensitive protein of human platelet membranes. Proc Natl Acad Sci USA 68: 240-243, 1971

19. Borsotti P, Ghilardi C, Ostano P, Silini A, Dossi R, Pinessi D, Foglieni C, Scatolini M, Lacal PM, Ferrari R, et al: Thrombospondin-1 is part of a Slug-independent motility and metastatic program in cutaneous melanoma, in association with VEGFR-1 and FGF-2. Pigment Cell Melanoma Res 28: 73-81, 2015.

20. Jayachandran A, Anaka M, Prithviraj P, Hudson C, McKeown SJ, Lo PH, Vella LJ, Goding CR, Cebon J and Behren A Thrombospondin 1 promotes an aggressive phenotype through epithelial-to-mesenchymal transition in human melanoma. Oncotarget 5: 5782-5797, 2014

21. Pal SK, Nguyen CT, Morita KI, Miki Y, Kayamori K, Yamaguchi A and Sakamoto K: THBS1 is induced by TGFB1 in the cancer stroma and promotes invasion of oral squamous cell carcinoma. J Oral Pathol Med 5: 730-739, 2016.

22. Roberts DD: Regulation of tumor growth and metastasis by thrombospondin-1. FASEB J 10: 1183-1191, 1996.

23. Nie S, Lo A, Wu J, Zhu J, Tan Z, Simeone DM, Anderson MA, Shedden KA, Ruffin MT and Lubman DM: Glycoprotein biomarker panel for pancreatic cancer discovered by quantitative proteomics analysis. J Proteome Res 13: 1873-1884, 2014.

24. Lyu T, Jia N, Wang J, Yan X, Yu Y, Lu Z, Bast RC Jr, Hua K and Feng W: Expression and epigenetic regulation of angiogenesisrelated factors during dormancy and recurrent growth of ovarian carcinoma. Epigenetics 8: 1330-1346, 2013.

25. Perez-Janices N, Blanco-Luquin I, Tuñón MT, Barba-Ramos E, Ibáñez B, Zazpe-Cenoz I, Martinez-Aguillo M, Hernandez B Martínez-Lopez E, Fernández AF, et al: EPB41L3, TSP-1 and RASSF2 as new clinically relevant prognostic biomarkers in diffuse gliomas. Oncotarget 6: 368-380, 2015.

26. Nomura S, Yoshitomi H, Takano S, Shida T, Kobayashi S Ohtsuka M, Kimura F, Shimizu H, Yoshidome H, Kato A, et al: FGF10/FGFR2 signal induces cell migration and invasion in pancreatic cancer. Br J Cancer 99: 305-313, 2008.

27. Behrens C, Lin HY, Lee JJ, Raso MG, Hong WK, Wistuba, II and Lotan R: Immunohistochemical expression of basic fibroblast growth factor and fibroblast growth factor receptors 1 and 2 in the pathogenesis of lung cancer. Clin Cancer Res 14: 6014-6022, 2008
28. Bane AL, Pinnaduwage D, Colby S, Reedijk M, Egan SE, Bull SB, O'Malley FP and Andrulis IL: Expression profiling of familial breast cancers demonstrates higher expression of FGFR2 in BRCA2-associated tumors. Breast Cancer Res Treat 117: 183-191, 2009.

29. Byron SA, Gartside MG, Wellens CL, Mallon MA, Keenan JB, Powell MA, Goodfellow PJ and Pollock PM: Inhibition of activated fibroblast growth factor receptor 2 in endometrial cancer cells induces cell death despite PTEN abrogation. Cancer Res 68: 6902-6907, 2008

30. Byron SA and Pollock PM: FGFR2 as a molecular target in endometrial cancer. Future Oncol 5: 27-32, 2009.

31. Han N, Kim MA, Lee HS and Kim WH: Evaluation of fibroblast growth factor receptor 2 expression, heterogeneity and clinical significance in gastric cancer. Pathobiology 82: 269-279, 2015.

32. Ahn S, Lee J, Hong M, Kim ST, Park SH, Choi MG, Lee JH, Sohn TS, Bae JM, Kim S, et al: FGFR2 in gastric cancer: protein overexpression predicts gene amplification and high $\mathrm{H}$-index predicts poor survival. Mod Pathol 29: 1095-1103, 2016.

33. Zhang J, Zhou Y, Jiang K, Shen Z, Ye Y and Wang S: Evaluation of the seventh AJCC TNM staging system for gastric cancer: a meta-analysis of cohort studies. Tumour Biol 35: 8525-8532, 2014.

34. Tokunaga R, Imamura $Y$, Nakamura K, Ishimoto T, Nakagawa S, Miyake K, Nakaji Y, Tsuda Y, Iwatsuki M, Baba Y, et al: Fibroblast growth factor receptor 2 expression, but not its genetic amplification, is associated with tumor growth and worse survival in esophagogastric junction adenocarcinoma. Oncotarget 7: 19748-19761, 2016.

35. Nakazawa K, Yashiro M and Hirakawa K: Keratinocyte growth factor produced by gastric fibroblasts specifically stimulates proliferation of cancer cells from scirrhous gastric carcinoma. Cancer Res 63: 8848-8852, 2003.

36. Sommer A, Kopitz C, Schatz CA, Nising CF, Mahlert C, Lerchen HG, Stelte-Ludwig B, Hammer S, Greven S, Schuhmacher J, et al: Preclinical efficacy of the auristatinbased antibody-drug conjugate BAY 1187982 for the treatment of FGFR2-positive solid tumors. Cancer Res 76: 6331-6339, 2016.

37. Tanaka K, Sonoo H, Kurebayashi J, Nomura T, Ohkubo S, Yamamoto $\mathrm{Y}$ and Yamamoto S: Inhibition of infiltration and angiogenesis by thrombospondin-1 in papillary thyroid carcinoma. Clin Cancer Res 8: 1125-1131, 2002.

38. Maeda K, Nishiguchi Y, Yashiro M, Yamada S, Onoda N, Sawada T, Kang SM and Hirakawa K: Expression of vascular endothelial growth factor and thrombospondin-1 in colorectal carcinoma. Int J Mol Med 5: 373-378, 2000.

39. Clezardin P, Frappart L, Clerget M, Pechoux C and Delmas PD: Expression of thrombospondin (TSP1) and its receptors (CD36 and CD51) in normal, hyperplastic, and neoplastic human breast. Cancer Res 53: 1421-1430, 1993.

40. Kasper HU,Ebert M, Malfertheiner P, Roessner A, Kirkpatrick CJ and Wolf HK: Expression of thrombospondin-1 in pancreatic carcinoma: correlation with microvessel density. Virchows Archiv 438: 116-120, 2001.

41. Grossfeld GD, Ginsberg DA, Stein JP, Bochner BH, Esrig D, Groshen S, Dunn M, Nichols PW, Taylor CR, Skinner DG, et al: Thrombospondin-1 expression in bladder cancer: Association with $\mathrm{p} 53$ alterations, tumor angiogenesis, and tumor progression. J Natl Cancer Inst 89: 219-227, 1997.

42. Kwak C, Jin RJ, Lee C, Park MS and Lee SE: Thrombospondin-1, vascular endothelial growth factor expression and their relationship with p53 status in prostate cancer and benign prostatic hyperplasia. BJU Int 89: 303-309, 2002.

43. Lin XD, Chen SQ, Qi YL, Zhu JW, Tang Y and Lin JY: Overexpression of thrombospondin-1 in stromal myofibroblasts is associated with tumor growth and nodal metastasis in gastric carcinoma. J Surg Oncol 106: 94-100, 2012.

44. Nakao T, Kurita N, Komatsu M, Yoshikawa K, Iwata T, Utsunomiya T and Shimada M: Expression of thrombospondin-1 and Ski are prognostic factors in advanced gastric cancer. Int J Clin Oncol 16: 145-152, 2011

45. Zhang J, Ito R, Oue N, Zhu X, Kitadai Y, Yoshida K, Nakayama H and Yasui W: Expression of thrombospondin-1 is correlated with microvessel density in gastric carcinoma. Virchows Archiv 442: $563-568,2003$

46. Radziwon-Balicka A, Santos-Martinez MJ, Corbalan JJ, O'Sullivan S, Treumann A, Gilmer JF, Radomski MW and Medina C: Mechanisms of platelet-stimulated colon cancer invasion: Role of clusterin and thrombospondin 1 in regulation of the P38MAPK-MMP-9 pathway. Carcinogenesis 35: 324-332, 2014. 
47. Firlej V, Mathieu JR, Gilbert C, Lemonnier L, Nakhlé J, Gallou-Kabani C, Guarmit B, Morin A, Prevarskaya N, Delongchamps NB, et al: Thrombospondin-1 triggers cell migration and development of advanced prostate tumors. Cancer Res 71: 7649-7658, 2011.

48. Wang TN, Qian X, Granick MS, Solomon MP, Rothman VL, Berger DH and Tuszynski GP: Thrombospondin-1 (TSP-1) promotes the invasive properties of human breast cancer. J Surg Res 63: 39-43, 1996

49. Yee KO, Connolly CM, Duquette M, Kazerounian S, Washington R and Lawler J: The effect of thrombospondin-1 on breast cancer metastasis. Breast Cancer Res Treat 114: 85-96, 2009.

50. Yu H, Tyrrell D, Cashel J, Guo NH, Vogel T, Sipes JM, Lam L, Fillit HM, Hartman J, Mendelovitz S, et al: Specificities of heparin-binding sites from the amino-terminus and type 1 repeats of thrombospondin-1. Arch Biochem Biophys 374: 13-23, 2000.

51. Taraboletti G, Rusnati M, Ragona L and Colombo G: Targeting tumor angiogenesis with TSP-1-based compounds: Rational design of antiangiogenic mimetics of endogenous inhibitors. Oncotarget 1: 662-673, 2010 .
52. Morandi V, Cherradi SE, Lambert S, Fauvel-Lafève F, Legrand YJ and Legrand C: Proinflammatory cytokines (interleukin-1 beta and tumor necrosis factor-alpha) down regulate synthesis and secretion of thrombospondin by human endothelial cells. J Cell Physiol 160: 367-377, 1994.

53. Loganadane LD, Berge N, Legrand C and Fauvel-Lafève F: Endothelial cell proliferation regulated by cytokines modulates thrombospondin-1 secretion into the subendothelium. Cytokine 9: 740-746, 1997.

54. Doll JA, Reiher FK, Crawford SE, Pins MR, Campbell SC and Bouck NP: Thrombospondin-1, vascular endothelial growth factor and fibroblast growth factor- 2 are key functional regulators of angiogenesis in the prostate. Prostate 49: 293-305, 2001.

55. Tarkkonen K, Ruohola J and Härkönen P: Fibroblast growth factor 8 induced downregulation of thrombospondin 1 is mediated by the MEK/ERK and PI3K pathways in breast cancer cells. Growth Factors 28: 256-267, 2010.

56. Dailey L, Ambrosetti D, Mansukhani A and Basilico C: Mechanisms underlying differential responses to FGF signaling. Cytokine Growth Factor Rev 16: 233-247, 2005.

57. Hong L, Han Y, Liu J and Brain L: Fibroblast growth factor receptor 2: A therapeutic target in gastric cancer. Expert Rev Gastroenterol Hepatol 7: 759-765, 2013. 